\title{
КОНЦЕПЦИЯ КРЕАТИВНОГО ГОРОДА В УСЛОВИЯХ ГЛОБАЛИЗАЦИИ И ПРОМЫШЛЕННОЙ РЕВОЛЮЦИИ («ИНКЛЮЗИВНЫЙ ГОРОД 5.0»)
}

\section{THE CONCEPT OF A CREATIVE CITY IN THE CONTEXT OF GLOBALIZATION AND THE INDUSTRIAL REVOLUTION ("INCLUSIVE CITY 5.0")}

\section{A. Grunichev M. Safiullin M. Gafarov}

Summary: The dynamics that have taken place in the last two decades in the formation of the structure of urban settlements in the national economy of the Russian Federation dictates the need to move the public administration system to a fundamentally new «rails» and decisionmaking paradigm. Otherwise, there may be threats to the sustainability of economic growth and social development. This article is devoted to understanding and partial solution of the questions raised. In it, the authors, on the basis of identified trends of the world economy, the globalization of the socio-economic environment, the diffusion of digital transformation offer their own view on the issue of balanced development of urban settlements in Russia through the prism of the proposed paradigm, the concept of "Inclusive city 5.0 ".

Keywords: city, inclusive growth, balanced development, globalization, sustainability, economic development, creative development, quality of life, national system, productive factors.
Груничев Александр Станиславович

К.э.н., ФГАУ «Учебно-методический чентр» Федеральной антимонопольной службы» (2. Казань)

C.p@tatar.ru

Сафиуллин Марат Рашитович,

Д.э.н., профрессор, директор, ГБУ «Центр перспективных экономических исследований Академии наук Республики Татарстан» (2. Казань)

Marat.Safiullin@tatar.ru

Гафаров Марат Ринатович

К.э.н., Н.С., ГБУ «Центр перспективных экономических исследований АН РТ» (2. Казань)

Аннотация: Динамика, которая имеет место быть в последние два десятилетия в формировании структуры городских поселений в национальной экономике РФ диктует необходимость перехода системы государственного управления на принципиально новые «рельсы» и парадигму принятия решений. В противном случае могут наметиться угрозы устойчивости экономического роста и социального развития. Осмыслению и частичному решению поставленных вопросов и посвящена настоящая статья. В ней авторы, на основе обозначенных трендов развития мировой экономики, глобализации социально-экономической среды, диффузии цифровых трансформаций предлагают собственный взгляд на проблему сбалансированного развития системы городских поселений в РФ через призму выдвигаемой парадигмы, концепции «Инклюзивный город 5.0».

Ключевые слова: город, инклюзивный рост, сбалансированное развитие, глобализация, устойчивость, экономическое развитие, креативное развитие, качество жизни, национальная система, производительные факторы.
( лобализация, многоукладность социально-экономической среды, ее динамическая трансформация во времени под давлением внешней и внутренней конъюнктуры и институциональной действительности, обусловленной во многом процессами цифровой трансформации социально-экономического уклада, формируют необходимость определения и обоснования направлений развития экономических систем в новых, меняющихся условиях. Скорость реакции на внешние и внутренние изменения, гибкость и адаптивность экономических систем в новую цифровую эпоху должна принципиально возрасти. Прежние, традиционные модели, ориентированные преимущественно на поиск экономических факторов роста, не отвечают требованиям, выдвигаемых современным обществом относительно перспектив и качества развития. Часто действующая система управления и инфраструктура организации хозяйственных процессов, заложенная в прошлую эпоху, не отвечает проявляющимся требованиям. В этой связи правительства, бизнес, научное сообщество начинают искать новые решения, способствующие процветанию национальной экономики в новых реалиях. Данная позиция во многом синхронизируется с подходом Акоффа Р.Л., Магидсона Дж., Эддисона Г.Дж. [1]. В соответствии с их теорией идеализированного проектирования, сегодня при таких радикальных изменениях необходим новый подход к планированию, когда образом жизни становятся непрерывные инновации и прорывные действия во всех аспектах управления и построения процессов.

Поставленная проблема сформировала условия активизации усилий в области ее решения. Все чаще В научно-публицистическом пространстве начинают встречаться работы [2, 3, 4], ориентированные на исследование ключевых, системообразующих производительных факторов, соответствующих современным требованиям развития. Важнейшие из этих работ обращают внимание на необходимость использования в модели 
экономического роста концепции инклюзивного роста, предусматривающей максимальную вовлеченность в создание конечного национального продукта экономических агентов. Более того идея инклюзивного развития концентрируется относительно и того, что процесс создания конечного продукта должен подразумевать вовлеченность в него не узкой группы хозяйствующих субъектов, а широкой базы всех слоев общественности. Только лишь в этом случае национальное богатство будет создаваться справедливым образом и распределяться таким же образом между всеми его участниками за счет обеспечения равных возможностей, генерирующихся в результате включения всего населения в систему создания и распределения валового внутреннего продукта (ВВП) $[5,6,7]$. На наш взгляд, наиболее точным по содержанию концепция инклюзивного роста отражена в работе Н.В. Пахомовой, К.К. Рихтера, Г.Б. Малышкова [8]. В ней авторы придерживаются структурного подхода к изучению теории инклюзивного роста. Это означает, что «всеобъемлющий» рост формируется лишь в том случае, если наблюдается структурное развитие экономики на фоне реализации антидискриминационной государственной политики, определяющей возможности самореализации для всех слоев населения. В этой связи авторы выделяют четыре основных направления, раскрывающих эффективность содержания ключевых принципов инклюзивного роста:

1. рост входных производительных ресурсов (трудовых, естественных, финансовых и т.п., в том числе за счет повышения эффективности их использования);

2. наращивание эффективности функционирования секторов экономики за счет повышения уровня энергоэффективности, обновления основных фондов, обеспечивающих эффекты снижения выбросов и повышения общего уровня экологического благополучия, перехода к альтернативным источникам энергии;

3. инфраструктурное развитие (жилищно-коммунальное хозяйство, энергетика, газо-, водоснабжение, перевозки пассажиров общественным транспортом, дороги и т.д.);

4. формирование условий для активизации инновационных процессов в экономике, включающих в себя ориентиры не только на создание продуктовых инноваций, но и процессных, содержащих, в частности, использование «зеленых» технологий производства и оказания услуг.

Важно отметить, что актуальность вопроса об инклюзивном, всеобъемлющем, справедливом для общества развитии присуща не только социально-экономическим системам регионального и национального уровня, но и муниципального (городского).
Это обусловлено тем, что процессы глобализации, предопределившие трансформацию индустриальной экономики в инновационную, наиболее сильно отразились на городах - основных центрах промышленного производства. В этих условиях скорость реакции на внешние и внутренние изменения, гибкость и адаптивность городов в новую цифровую эпоху должны принципиально возрасти $[9,10,11]$. Часто действующая система управления и сформировавшаяся институциональная основа, заложенная в прошлые периоды, не отвечает проявляющимся требованиям, характерным для шестого технологического уклада. В связи с этим, формирующийся эволюционный этап требует не только пересмотра концепции управления социально-экономическими системами, но и выработки конкретных решений или направлений, обеспечивающих адаптивность их функционирования в динамично трансформирующейся внешней и внутренней среде. Как уже ранее отмечалось подобная постановка вопроса актуальна, прежде всего, для городского каркаса национальной экономики.

Исследование развития городов представляет сегодня интерес не только с позиции выбора и обоснования моделей, определяющих потенциал их социально-экономического роста, но и с точки зрения набирающих оборотов темпов перетока населения из малых городов в более крупные. Согласно данным, полученных в рамках состоявшихся в 2002 и 2010 годах всероссийской переписи населения, отмечается явный тренд сокращения числа малых городов (таблица 1, рисунок 1). При условии, что численность населения при этом в крупных городах имеет положительную тенденцию, снижение числа малых городских поселений ни есть ни что иное, как свидетельство миграции населения по вертикали городского каркаса вверх. К сожалению, на момент подготовки статьи результаты переписи населения, запланированную на 2020 год, не получены. Однако, учитывая наметившийся тренд, по всей видимости, ситуация не сильно измениться с точки зрения сформировавшихся тенденций.

Проявляющиеся тенденции во многом укрепляют формирующуюся в последние годы точку зрения, в соответствии с которой через 20 лет в России может остаться 20-30 крупнейших городов, в которых сосредоточится основная часть городского населения [13]. Несомненно, данная точка зрения носит в определенной степени радикальный характер, однако наблюдаемые тенденции формирования структуры городских поселений в России определяют необходимость самого пристального внимания к поставленному вопросу. В условиях высоких темпов глобализации человеческие, материальные и нематериальные активы будут повышать градус своей концентрации в промышленно-городских агломерациях. Это, в свою очередь, будет способствовать дальней- 
Группировка городских поселений в РФ по численности населения [12]

\begin{tabular}{|c|c|c|c|c|c|c|c|}
\hline & \multirow[t]{2}{*}{ Всего } & \multicolumn{6}{|c|}{ в том числе городские поселения с числом жителей } \\
\hline & & до 5000 & $5000-9999$ & $\begin{array}{l}10000- \\
19999\end{array}$ & $\begin{array}{l}20000- \\
49999\end{array}$ & $\begin{array}{c}50000- \\
99999\end{array}$ & $\begin{array}{c}1 \text { млн. и } \\
\text { более }\end{array}$ \\
\hline \multicolumn{8}{|c|}{2002 год } \\
\hline Число городских поселений & 2940 & 1020 & 683 & 524 & 383 & 163 & 13 \\
\hline \multicolumn{8}{|c|}{2010 год } \\
\hline Число городских поселений & 1734 & 504 & 529 & 391 & 238 & 59 & 13 \\
\hline
\end{tabular}

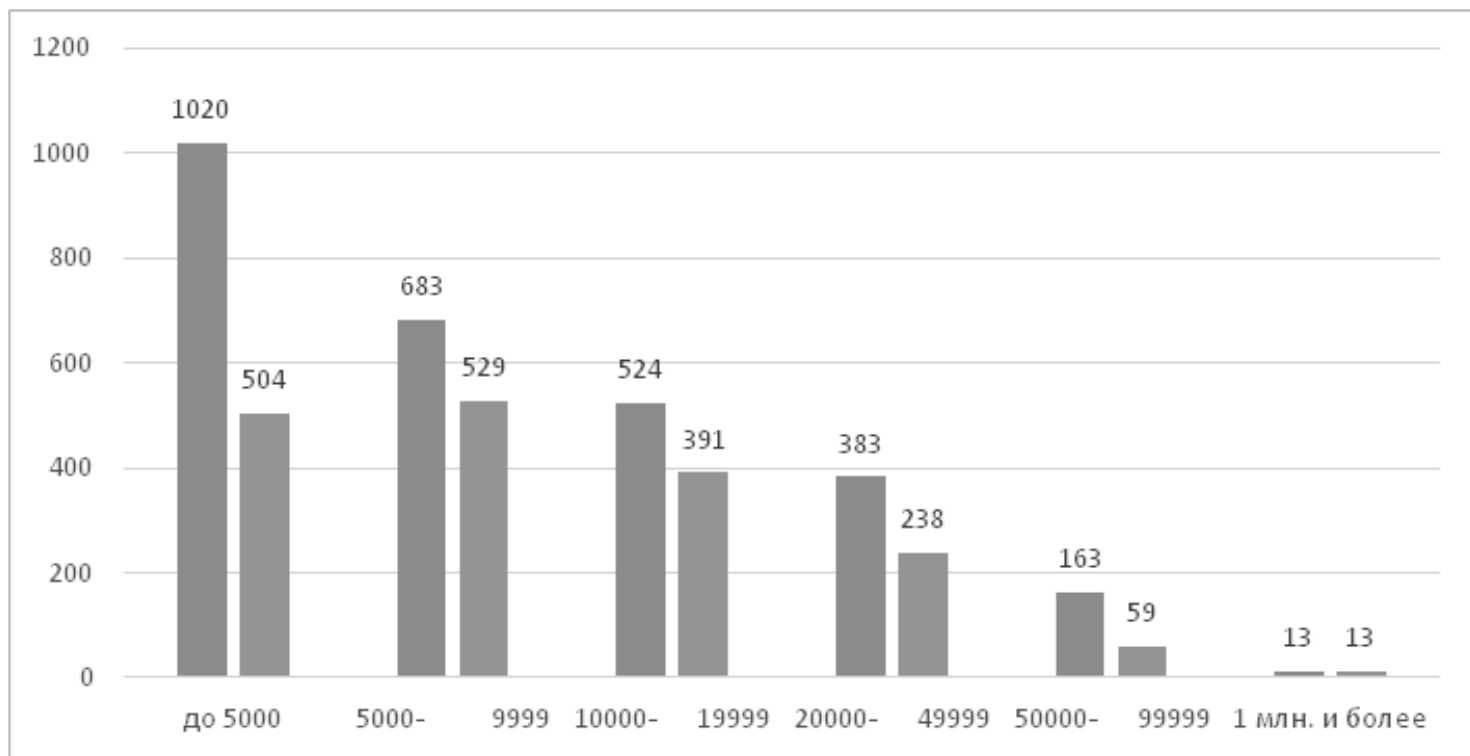

Рис. 1. Группировка городских поселений в РФ по численности населения [12]

шей реструктуризации городского расселения и оттока ресурсов из малых и средних городов в города-миллионники. По сути, речь идет о некой пирамиде, где в качестве вершины находятся крупнейшие мегаполисы, а на нижестоящих уровнях - города меньших масштабов. При этом конфигурация пирамиды имеет не постоянную (зыбкую) основу и склонна наращивать темпы «стирания» во времени более низких иерархических уровней. Во многом это обусловлено миграцией человеческих и материальных ресурсов малых городов в крупные ввиду наличия в последних более совершенной базы, предопределяющих количественно-качественные параметры их развития. При этом под «базой» здесь понимается как наличие развитой социальной и экономической инфраструктуры, обуславливающей более высокие нормы отдачи и потенциал развития экономических агентов, так и наличие соответствующих возможностей для самореализации. В формализованном виде данный подход представлен на рисунке 2.

Важнейшим фактором в этих условиях и трансформирующихся реалиях, предопределяющим сохранение устойчивого положения «пирамиды» становится поиск механизмов и путей, ограничивающих подобные миграционные сдвиги в целях сохранения устойчивого и эффективного развития городов любой размерности. При этом необходимо отметить, что этот вопрос не относится к категории тривиальных. На наш взгляд одним из направлений, способных обеспечить его решение является создание и активное продвижение модели инклюзивного роста. Опираясь на нее, а также учитывая специфику городских социально-экономических систем со всем многообразием их внутренней и внешней среды, представляется целесообразным системное развитие городов, подразумевающее, в том числе, ориентацию стратегии на креативные модели развития социальной и экономической среды. Под креативностью, при этом, мы понимаем нестандартные, адаптивные новым реалиям механизмы роста, обеспечивающие комфортность проживания в городах, не зависимо от концентрации в них ресурсов, а также формирующие основу для ускоренного развития экономики.

На наш взгляд данная креативность должна формироваться в рамках следующих пяти ключевых направлений: 


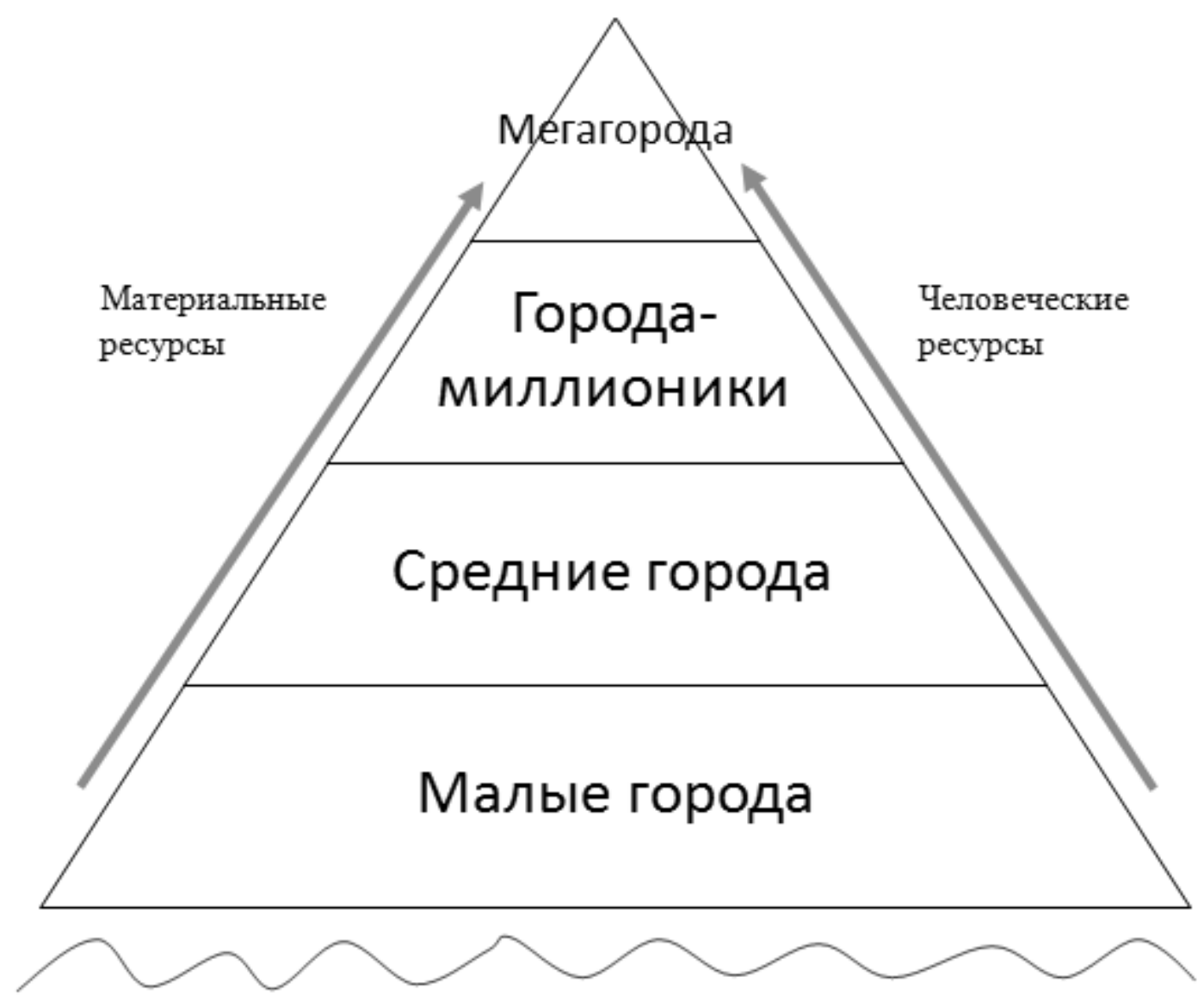

Неустойчивость основы «пирамиды» и ее низших звеньев

Рис. 2. Группировка городских поселений в РФ по численности населения [12]

- креативная экономика;

- креативный социальный класс;

- креативные коммуникации;

- инфраструктурная логика;

- цифровые сервисы.

В нашей интерпретации данный подход получил название концепция «Инклюзивный город 5.0». Более детальное рассмотрение основных компонент предлагаемой концепции представлено ниже.

Концепция «креативной экономики» заключается в исследовании взаимосвязи экономики и креативности на фоне сдвига экономических приоритетов от «финансов» к «идеям», «способностям» и «обучаемости», как основополагающим принципам экономического успеха. Данный подход обусловлен тем, что в условиях четвертой промышленной революции важнейшими генераторами экономического роста являются нематериальные ресурсы, в виде, к примеру, репутационного капитала; знаний, предопределяющих конвертацию производи- тельных факторов в систему макроэкономических эффектов; новые идеи, соответствующие «духу» все более активно проницающего социально-экономическую среду шестого технологического уклада. Данный подход обуславливает необходимость развития креативного мышления и методов организации трудовых и материальных ресурсов с последующей их конвертациекй в макроэкономический рост.

Под концепцией креативного социального класса понимается обеспечение условий, формирующих социальный слой, ориентированный на проектирование и создание инноваций. Общеизвестно, что инновации - это двигатель современной экономики. В этой связи крайне важно сформировать такие условия в городской среде, которые бы способствовали активизации процессов инновационных решений и разработок. В противном случае генерируемые инициативы будут гаснуть и не получать соответствующего отклика, что впоследствии может подтолкнуть межгородские миграционные процессы с целью самореализации индивидуума в более 
благоприятных условиях.

Концепция «инфраструктурная логика» предполагает выработку решений, направленных на формирование стратегии развития города «от управления активами к управлению доступом к ним». В цифровую эпоху кардинально меняются требования к управлению и инфраструктуре. Логика, ориентированная на хозяйственное, рациональное управление активами не способствует решению научных, технологических и другого рода актуальных задач. Требуется принципиальное переосмысление управленческих подходов с целью создания условий, способствующих расширению условий доступа экономических агентов к инфраструктурным активам города: помещениям, оборудованию, информационным сервисам, культурным ценностям, инвестициям, доступу к прочим благам качества жизни. Другими словами, управление инфраструктурой города как объектом не должно замыкаться на построение процессов его содержания и управления в рамках существующих регламентов и нормативов. Управленческая парадигма должна отталкиваться от того, что инфраструктура - это возможности, которые необходимо предоставлять экономическим агентам для их самореализации и решения народнохозяйственных задач.

Концепция «креативные коммуникации» опирается на необходимость развития кросс-культурных, кроссэтнических, кросс-конфессиональных коммуникаций в городе. Городская среда, характеризующая комфортность проживания, определяется не только и не столько экономическими и технологическими решениями, сколько духовными ценностями. В этой связи, несомненно, наряду с предложенными выше концептуальными подходами, важнейшим направлением становится развитие межкультурных коммуникаций. Последние, в свою очередь, определяют, как устойчивость социальной среды, нивелируя различного рода возможные социальные конфликты, так и способствуют устойчивому экономическому развитию города, как результат сбалансированного соотношения социальных и макроэкономических эффектов. При этом важно обратить внимание на то, что вопросы кросс-этнических и кросс-конфессиональных коммуникаций являются наиболее острыми, в условиях набирающих обороты гибридных, прокси войн на постсоветском пространстве и требующими повышенного внимания городских властей.

Наконец, концепция «цифровые сервисы» ориентирована на выработку направлений и оптимальных решений, обеспечивающих процессы интеллектуализации и цифровизации городских сервисов. Цифровая трансформация, как показывает практика последних лет, способна формировать не только целую серию положительных эффектов в виде, к примеру, роста производительности труда, но и выступать в целом в роли «локомотива» экономического роста. По сути, цифровая экономика - это инструментарий, ликвидирующий административные барьеры, повышающий прозрачность экономических отношений и активизирующий во многом процессы оптимизации хозяйственных процессов. Кроме того, что очень важно в контексте теории инклюзивного роста. Диффузия цифровых технологий может стимулировать эконмическую динамику за счет создания дополнительных возможностей для занятости, расширения диапазона использования новых технологических решений, наращивания экономических связей, активизации процессов вовлеченности экономических агентов в систему распределения общественных благ и т.п. Также использование цифровых технологий в хозяйственной деятельности может способствовать выходу на новые рынки, в том числе и внешние.

Несмотря на высокий уровень сложности и многоаспектности процесса обеспечения устойчивости городской системы через призму цифровой трансформации, его реализация всецело укладывается в парадигму П. Г. Щедровицкого [14]. В соответствии с ней важнейшим двигателем развития экономики является наличие и прогрессирование технологического предпринимательства, обеспечивающего оптимальное конфигурирование факторов производства, способствующего, в свою очередь, повышению прибыли и/или снижению затрат при выполнении операционных процессов на основе повышения производительности труда (или в рамках повышения эффективности использования всех факторов производства).

Необходимо отметить, что предлагаемая нами концепция развития структуры городских поселений, ориентированная на сохранение и устойчивость «городской пирамиды» в национальном масштабе, будет способствовать не только ее устойчивости, но и формировать стимулы равномерного распределения ресурсов, формируя тем самым «сглаженную» концентрацию человеческих, материальных и нематериальных ресурсов. Данный эффект будет возникать как следствие оптимального сочетания производительных факторов, обуславливающих потенциал роста и самореализации экономических агентов в городских поселениях разного масштаба. Важнейшим результатом станет устойчивость «пирамиды» городских поселений. Это, в свою очередь, предопределит совершенно иную парадигму развития национальной экономики, органично укладывающуюся как в теорию инклюзивного роста, так и способствующей росту качества жизни и благосостояния общества. 


\section{ЛИТЕРАТУРА}

1. Акофф Р.Л., Магидсон Дж., Эддисон Г.Дж. Идеализированное проектирование. / Пер.с англ. Ф.П. Тарасенко. —Днепропетровск: «Баланс БизнесБук», 2007.

2. Сафиуллин М.Р., Ельшин Л.А., Прыгунова М.И. Волатильность и конкурентоспособность регионов в условиях внешнеполитических и конъюнктурных изменений (на примере регионов Приволжского федерального округа). Вестник Российского экономического университета имени Г.В. Плеханова. 2014. № 12 (78). C. 115-127.

3. Hasmath R. Inclusive growth, development and welfare policy: A critical assessment. New York: Routledge Taylor \& Francis Group, 2015. 293 c. doi:10.4324/9781315732626

4. Feshari M., Valibeigi M. Determinants of inclusive growth in iranian regions (sure approach in panel data) // Regional Science Inquiry. 2017. T. 9. №. 1. C. 167-175.5. Anand, R., Tulin, V., and Kumar, N. (2014). India: Defining and Explaining Inclusive Growth and Poverty Reduction. IMF Working Paper No.14/63. Retrieved from http://www.imf.org/external/pubs/ft/wp/2014/wp1463.pdf

5. Felipe, J. (2012). Inclusive Growth: Why Is It Important for Developing Asia? The CADMUS Journal, 1(4), 36-58.

6. Мау В.В ожидании новой модели роста: социально-экономическое развитие России в 2013 году // Вопросы экономики. - 2014 - 12 - C. 4-32.

7. Н.В. Пахомова, К.К. Рихтер, Г.Б. Малышкова. Инклюзивный устойчивый рост: приоритеты, индикаторы, международный опыт, потенциал согласования с моделью реиндустриализации. Проблемы современной экономики. 2014. № 3 (51). С. 15-24.

8. Леонов С.Н. Город как модель и форма общественного развития (об учебнике «урбанистика. городская экономика, развитие и управление»). Пространственная экономика. 2020. Т. 16. № 1. С. 171-183.

9. Морозова Т.А., Селиверстова И.Г. Управление городским развитием как часть культурной политики. Муниципалитет: экономика и управление. 2018. № 2 (23). С. 59-62.

10. Кольба А.И. Политико-административное управление агломерациями: проблемы концептуализации. Южно-российский журнал социальных наук. 2019. Т. 20. № 3. С. 76-90.

11. Федеральная служба государственной статистики. URL: https://rosstat.gov.ru/vpn_popul (Режим доступа: 01.10.2020)

12. Проект убийства населения России агломерацией и резким снижением числа целей для ядерной атаки. URL: https://alexandr-palkin.livejournal. com/4430652.html (Режим доступа: 01.10.2020)

13. «Промышленная политика России — кто оплатит издержки глобализации» (совместно с Княгининым В.Н.). — Москва, Издательство «Европа», 2005. C. 160

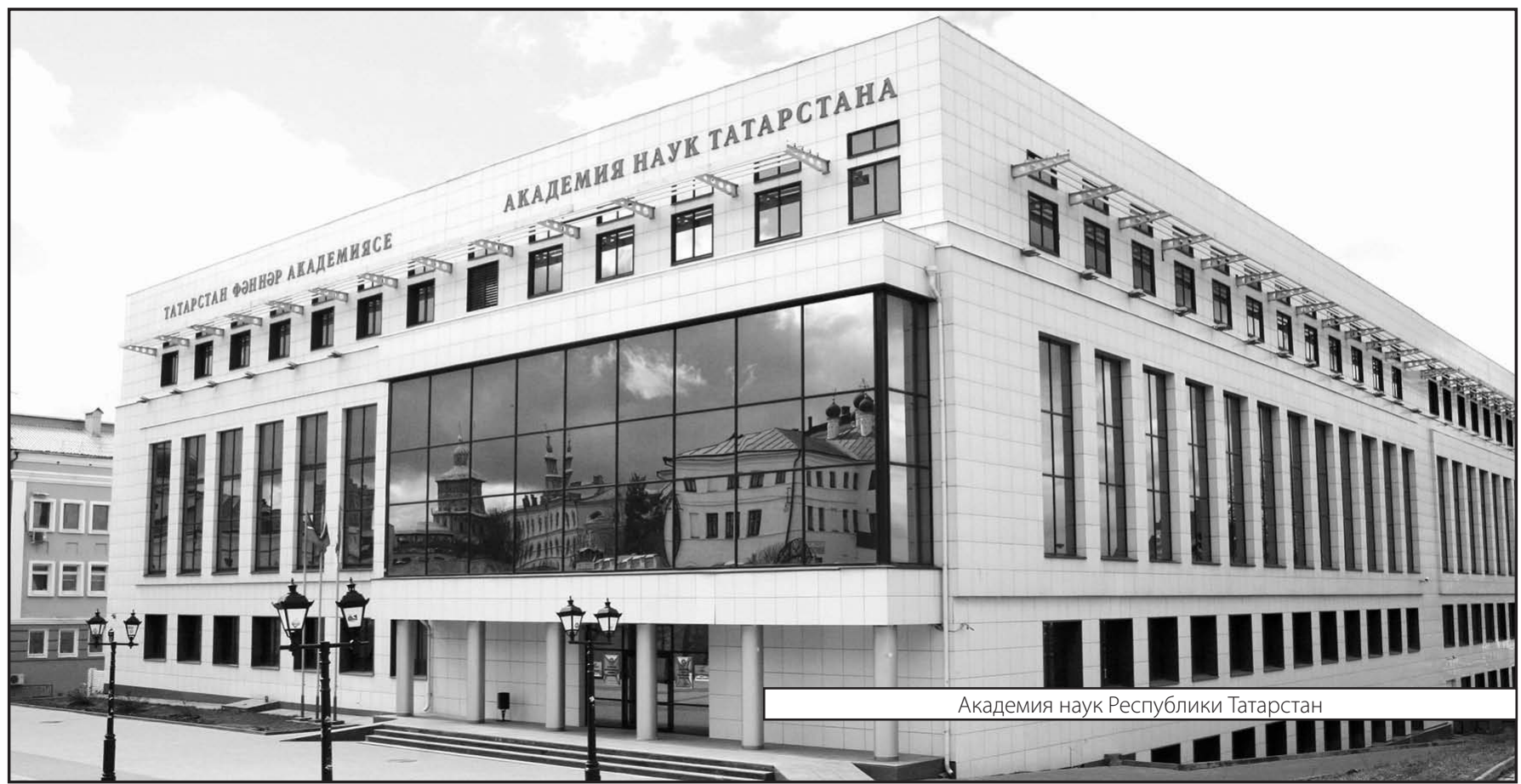

